\title{
Formation and Stability of Colloids Driven by Reducing Conditions: Impact on Water Quality
}

\author{
VINCENT NOËL ${ }^{1}$, NARESH KUMAR ${ }^{2}$, MAYA ENGEL ${ }^{3}$, \\ KRISTIN BOYE ${ }^{1}$, GORDON E. BROWN JR. ${ }^{1,3}$, JOHN R. \\ BARGAR $^{1}$ \\ ${ }^{1}$ SLAC National Accelerator Lab, Menlo Park, CA, USA \\ ${ }^{2}$ University of Vienna, Vienna, Austria \\ ${ }^{3}$ Stanford University, Stanford, CA, USA
}

Colloids mediate the mobility of nutrients, heavy metals, and radionuclides in sediments that experience strong wet-dry cycling and impact groundwater quality. Sulfidation of Fe(III)-hydroxide nanoparticles has been proposed to generate sulfidic colloids. However, their nature and the parameters controlling their formation and stability are not well understood. Such information would improve understanding of their impact on water quality.

We observed that reductive dissolution of ferrihydrite by aqueous sulfide generates nano-scale FeS clusters. We found that their subsequent aggregation, which promotes settling of $\mathrm{FeS}$ aggregates into the solid fraction, is directly correlated with sulfide/Fe ratio. At sulfide/Fe ratios $\leq 0.5$, FeS clusters and larger colloids remained in suspension for at least 14 days (and up to several months). These suspended FeS clusters/colloids can sorb and transport contaminant ions in groundwater. At sulfide $/ \mathrm{Fe}$ ratios $>0.5$, sulfidation reaction rates were rapid and $\mathrm{FeS}$ cluster aggregation was accelerated. Moreover, the presence of organic compounds increased the time of suspension of FeS colloids. Finally, we found that in fresh groundwater systems poor in sulfate (lakes, floodplains, peatlands), sulfidation of ferrihydrite generates FeS colloids that remain suspended over long time periods, thus mobilizing a substantial fraction of the $\mathrm{Fe}$ and sulfide budgets.

Our results provide a conceptual model for predicting under what conditions $\mathrm{FeS}$ colloids form and enhance or inhibit the mobility of contaminants and nutrients associated with them. Moreover, our observations provide additional clarification of the role of Fe- and S-mineral redox cycling on the mobility of organic compounds, and their contributions to the mobility of contaminants. 